\title{
Vasopressin and oxytocin release during prolonged environmental hypoxia in the rat
}

\author{
H Kelestimur, R M Leach, J P T Ward, M L Forsling
}

\begin{abstract}
Background - The mechanism causing peripheral oedema in hypoxaemic chronic obstructive pulmonary disease has not been established. Vasopressin, a powerful antidiuretic hormone involved in salt and water homeostasis, is released in response to acute hypoxia. However, the effect of prolonged hypoxaemia on hypothalamic and pituitary release of the magnocellular hypothalamic hormones, vasopressin and oxytocin, has not previously been studied. Methods - Male Wistar rats were randomly allocated to either normobaric, hypoxic

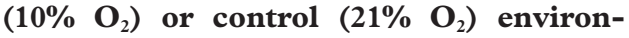
mental chambers. An initial series of experiments examined plasma vasopressin concentration, osmolality, sodium concentration, packed cell volume (PCV), and weight gain at weekly intervals $(n=4-6)$ for six weeks. The maximum increase in plasma vasopressin concentration and PCV occurred after five weeks. In a second experiment vasopressin and oxytocin concentrations in the hypothalamus, pituitary gland, and plasma were measured in eight control and eight hypoxic rats after five weeks in the environmental chambers.
\end{abstract}

Results - In rats exposed to environmental hypoxia PCV increased $(\mathrm{p}<0.001)$ and weight gain decreased $(p<0.05)$ compared with controls. The plasma vasopressin concentration increased progressively from a baseline of $1.36(0.2) \mathrm{pmol} / 1(\mathrm{n}=6)$ to a maximum of $4.38(0.8) \mathrm{pmol} / 1(\mathrm{n}=$ $6 ; p<0.01$ ) during the first five weeks of environmental hypoxia (difference $\mathbf{3 . 0 2}$ (95\% CI 1.18 to 4.86$)$ ). Plasma osmolality and sodium concentration were unchanged in hypoxic rats compared with controls during the six week period. The hypothalamic vasopressin concentration was increased $(p<0.001)$ after five weeks of environmental hypoxia (91.6 (4.8) pmol/ hypothalamus) compared with controls (57.4 (5.1) $\mathrm{pmol} / \mathrm{hypothalamus),} \mathrm{the} \mathrm{differ-}$ ence being $34.2 \mathrm{pmol} / \mathrm{hypothalamus}(95 \% \mathrm{CI}$ 21.6 to 46.5 ). The pituitary vasopressin concentration was unchanged. In hypoxic rats hypothalamic oxytocin (59.6 (3.2) pmol/hypothalamus) was greater $(\mathrm{p}<0.01)$ than in controls (42 (3.8) pmol/hypothalamus), a difference of $17.6 \mathrm{pmol} /$ hypothalamus (95\% CI 8.7 to 26.5$)$. Similarly, the plasma oxytocin concentration was increased $(p<0.05)$ in hypoxic rats $(6.78$ (1.2) pmol/1) compared with controls $(3.3(0.8) \mathrm{pmol} / \mathrm{l})$, a difference of
$3.48 \mathrm{pmol} / 1$ (95\% CI 0.89 to 6.07$)$. The pituitary oxytocin concentration was unchanged in the two groups.

Conclusions - These results demonstrate an increase in hypothalamic production of vasopressin and oxytocin in rats during prolonged hypoxaemia. Increased plasma concentrations of neurohypophysial hormones would be expected to impair sodium and water homeostasis in patients with hypoxaemia. However, the absence of change in the plasma osmolality and sodium concentrations in this study and previous clinical investigations suggests that compensatory mechanisms modulate the actions of both vasopressin and oxytocin. A reduction in renal blood flow or decreased renal responsiveness to the neurohypophyseal hormones may be involved.

(Thorax 1997;52:84-88)

Keywords: vasopressin, oxytocin, hypoxaemia, rats.

Peripheral oedema may develop in a proportion of patients with hypoxaemic chronic obstructive pulmonary disease (COPD). ${ }^{1}$ The cause of this fluid retention is unclear but heart failure is not a factor as cardiac output is maintained. ${ }^{2}$ Both an increase in vasopressin concentration and altered renal function have been proposed as potential mechanisms. ${ }^{34}$ The plasma vasopressin concentration increases in several species including man during acute hypoxia..$^{5-7}$ However, the effect of prolonged hypoxia on vasopressin homeostasis has not been established. Early clinical studies in hypoxaemic COPD reported increased plasma vasopressin concentrations in oedematous patients. ${ }^{48}$ In contrast, a recent study reported that vasopressin levels and osmolality were not significantly different in hypoxaemic patients with or without peripheral oedema although there was a trend towards an increase in the oedematous group. ${ }^{3}$ The antidiuretic and natriuretic effects of a raised plasma vasopressin concentration would be expected to impair sodium and water homeostasis. ${ }^{45}$ However, the increased vasopressin level may be an appropriate homeostatic response to hypoxia induced changes in renal function, ${ }^{3910}$ the renin-angiotensin system, ${ }^{411}$ and the autonomic nervous system. ${ }^{312}$ The role of oxytocin during hypoxia is unknown but, like vasopressin, it is a neurohypophyseal hormone with natriuretic properties. $^{13}$

A clear understanding of the role of hypothalamic hormones in water homeostasis 
during hypoxia is an important requirement if the mechanism that causes peripheral oedema in some patients with hypoxaemic COPD is to be resolved. The aim of this study was to determine the effect of prolonged hypoxia on hypothalamic production, pituitary release, and plasma concentrations of vasopressin and oxytocin. A well established rat model for neurohypophyseal studies was used to enable hypothalamic and pituitary hormone measurements to be made. Plasma sodium concentrations and osmolality were measured to determine the functional effects of the plasma concentrations of vasopressin and oxytocin.

\section{Methods}

Age and weight matched male Wistar rats $(250-350 \mathrm{~g})$ were randomly assigned to two groups and maintained in two identical normobaric environmental chambers for periods of 7-42 days. A control group breathed air throughout the experimental period. The second group was exposed to an atmosphere in which the oxygen content was progressively reduced over 14 days and then held constant at $10 \%$. The oxygen content was monitored continuously (Servomex $\mathrm{O}_{2}$ analyser OA 580, Sybron-Taylor), recorded at 10 minute intervals, and maintained at $10(1) \%$ by displacing air with nitrogen. The chambers were opened every two days for cleaning and feeding but hypoxic conditions were re-established within 60 minutes. The carbon dioxide concentration in the chamber was monitored continuously (Horiba PIR-2000, Horiba Ltd) and maintained below $0.5 \%$ by soda lime absorption. A 12 hour light/dark cycle was imposed and the temperature controlled at 22 (1) ${ }^{\circ} \mathrm{C}$ by a thermostat and freezer unit. Humidity in the chambers was maintained below $20 \%$ by silica crystal water absorption columns and the freezer units. The control rats were housed in the same room in an identical chamber but were allowed to breath room air $\left(21 \% \mathrm{O}_{2}\right)$. Arterial oxygen tensions in parallel groups from the same environments were determined from the tail artery blood and standard blood gas analysis (ABL3, Radiometer, Copenhagen, Denmark).

Rats ( $\mathrm{n}=4-6)$ were removed from the chambers at 08.30-09.00 hours at weekly intervals and killed by immediate decapitation. Trunk blood was collected for the determination of packed cell volume and plasma was separated for the determination of plasma sodium levels and osmolality. An aliquot was stored at $-20^{\circ} \mathrm{C}$ until the vasopressin level was determined by radioimmunoassay. In the second series of experiments the posterior lobe of the pituitary and the hypothalamus were dissected free directly following decapitation of rats $(n=8)$ that had been in the environmental chamber for five weeks. The hypothalamic tissue was homogenised in $0.4 \mathrm{M}$ acetic acid and the pituitary tissue in $0.2 \mathrm{M}$ acetic acid and the extracts were stored at $-20^{\circ} \mathrm{C}$ until assay.

\section{ANALYSES}

Plasma osmolality was determined by the method of depression of freezing point
(Digimatic Osmometer Model 3D2, Advanced Instrument Inc, Needham Heights, Massachusetts, USA). The sodium concentration was measured using a flame photometer (Corning, Halstead, Essex, UK) and the plasma vasopressin concentration was determined by radioimmunoassay after prior extraction using Sep Pak C18 cartridges (Water Associates Inc, Milford, Massachusetts, USA) ${ }^{14}$ using the first international standard for vasopressin (77/ 501). The lower limit of detection was 0.12 (0.02) pmol/1. The intra-assay and interassay coefficients of variation were $7.7 \%$ and $11.9 \%$, respectively, for $2.5 \mathrm{pmol} / 1$. The vasopressin content of the pituitary and hypothalamus was measured by radioimmunoassay also. ${ }^{15}$ Oxytocin was determined as described by Balment et al using the fourth international standard for oxytocin (76/575). ${ }^{16}$ The lower limit of detection was $1.6 \mathrm{pmol} / 1$ with intra-assay and interassay variations of $6.1 \%$ and $9.8 \%$, respectively, for $5 \mathrm{pmol} / \mathrm{l}$.

\section{STATISTICAL ANALYSIS}

Values are given as means (SE). The difference between hypoxic and control values with $95 \%$ confidence intervals (95\% CI) are also presented. In the first experiment two way analysis of variance (ANOVA) was used to compare changes within and between the hypoxic and control groups over time. In the second experiment differences between control and hypoxic values were compared using the Student's $t$ test. Differences were considered to be significant if $\mathrm{p}<0.05$.

\section{Results}

During the initial six week experimental period weight gain in rats exposed to environmental hypoxia was significantly reduced $(\mathrm{p}<0.05)$ in comparison with control animals (fig $1 \mathrm{~A}$ ). The progressive and significant increase in the packed cell volume (PCV) in blood from rats housed in the hypoxic environmental chamber is compared with that in controls in fig $1 \mathrm{~B}$. The PCV was $42(0.6) \%$ at week $0(n=6)$ compared with $58(1.5) \%$ at week $6(n=6$; $\mathrm{p}<0.001)$. The arterial oxygen tension in parallel groups of rats from the same environment was $47(2) \mathrm{mm} \mathrm{Hg}$ in hypoxic rats $(\mathrm{n}=17)$ and 91 (1) $\mathrm{mm} \mathrm{Hg}$ in control rats $(\mathrm{n}=17)$. Figure 2 demonstrates the corresponding increase in plasma vasopressin concentrations in the hypoxic rats compared with control rats $(p<0.01)$ during the six week experimental period. The maximum increase in vasopressin occurred after five weeks when the plasma concentration was $4.38(0.8) \mathrm{pmol} / \mathrm{l}(\mathrm{n}=6)$ compared with the baseline level of $1.36(0.2) \mathrm{pmol} / 1(\mathrm{p}<0.01$; $n=6)$ at the onset of the experimental period. The difference between the baseline and maximum vasopressin concentrations was 3.02 (95\% CI 1.18 to 4.86 ). The baseline plasma sodium concentration $(141(0.4) \mathrm{mmol} / \mathrm{l} ; \mathrm{n}=$ 6) and osmolality (285 (0.8) mosmol $/ \mathrm{kg} ; \mathrm{n}=$ 6) did not change throughout the experiment and were $140(0.9) \mathrm{mmol} / \mathrm{l}(\mathrm{n}=6)$ and 288 

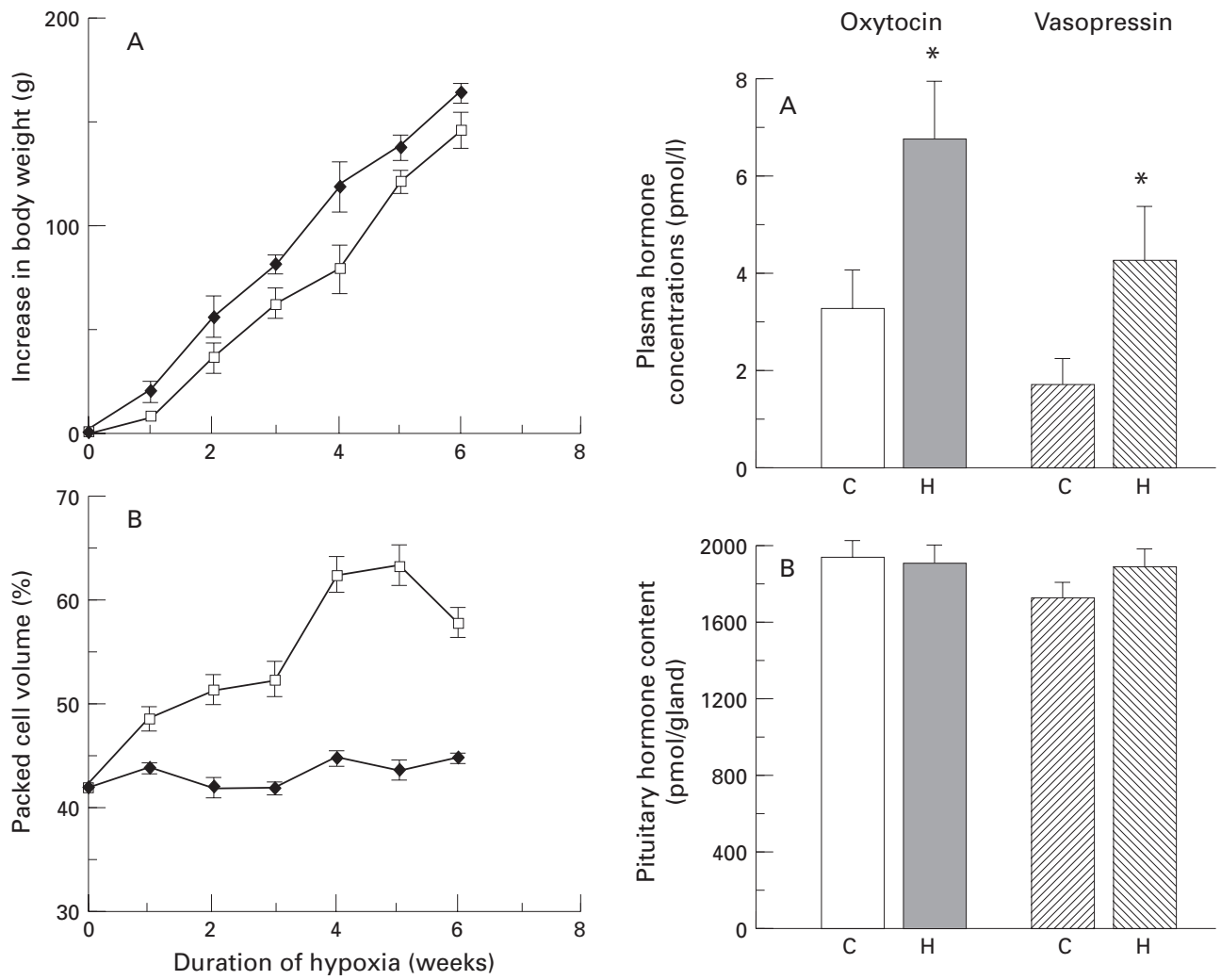

Figure 1 (A) Increase in body weight and (B) packed cell volume of blood (\%) during the six week experimental period in rats maintained in hypoxic $(\square)$ and control $(\bullet$ environmental chambers. The change in weight and packed cell volume was significantly different by two way analysis of variance in hypoxic rats compared with controls $(p<0.05)$.

(1.7) $\mathrm{mosmol} / \mathrm{kg}(\mathrm{n}=6)$, respectively, after six weeks.

The second experiment measured hypothalamic, pituitary, and plasma vasopressin and oxytocin concentrations following five weeks of exposure to environmental hypoxia or control conditions. Hypothalamic, pituitary, and plasma levels of vasopressin and oxytocin are reported in fig 3 . The hypothalamic vasopressin concentration was greater $(\mathrm{p}<0.001)$

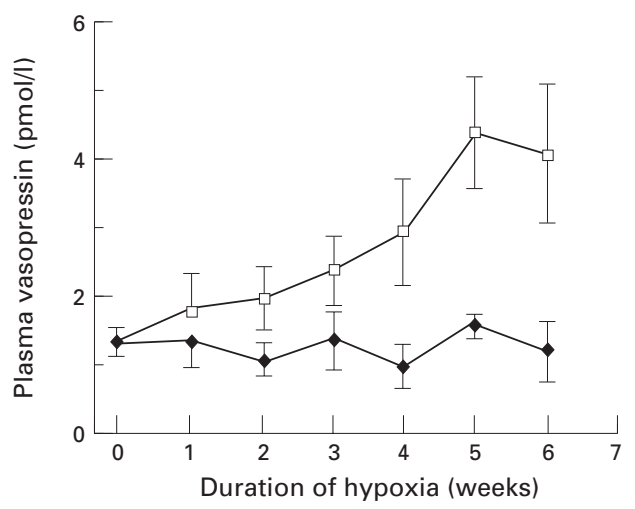

Figure 2 Comparison of plasma vasopressin concentrations in rats maintained in the hypoxic ( $\square$ ) and control ( ) environmental chambers during the six week experimental period. Plasma vasopressin concentrations increased significantly by two way analysis of variance in hypoxic rats compared with controls $(p<0.05)$.

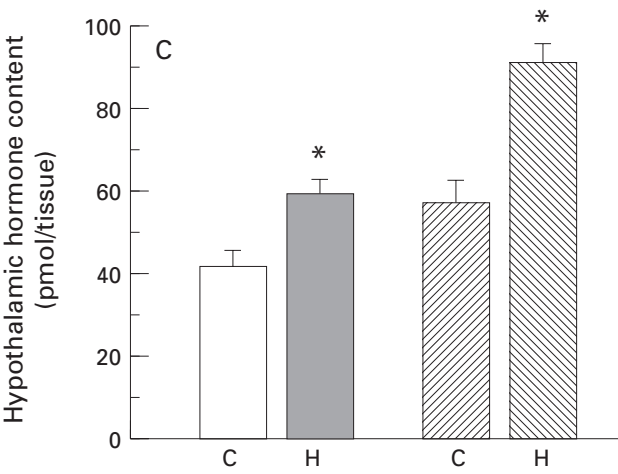

Figure 3 (A) Plasma, (B) pituitary, and (C)

hypothalamic concentrations of vasopressin and oxytocin in rats maintained for five weeks in hypoxic $(H)$ and control (C) environmental chambers. ${ }^{*} p<0.05$ (Student's $t$ test).

in hypoxic rats (91.6 (4.8) $\mathrm{pmol} /$ hypothalamus) than in controls (57.4 (5.1) pmol/hypothalamus), the difference between the two groups being $34.2 \mathrm{pmol} / \mathrm{hyp}$ pothalamus (95\% CI 21.6 to 46.5$)$. Pituitary vasopressin concentrations did not differ significantly between the two groups (1892 (92) versus 1740 (78) $\mathrm{pmol} / \mathrm{gland}$; difference in means $152 \mathrm{pmol} /$ gland (95\% CI -65 to 368$)$ ). As in the first experiment, the plasma vasopressin concentration was greater $(\mathrm{p}<0.05)$ in hypoxic rats (4.13 (1.10) pmol/l) than in controls (1.62 (0.54) pmol/1), the difference in means being $3.03 \mathrm{pmol} / 1$ (95\% CI 0.40 to 5.66$)$. The hypothalamic oxytocin concentration was greater $(\mathrm{p}<0.01)$ in hypoxic rats $(59.6$ (3.2) pmol/ hypothalamus) than in control rats (42 (3.8) $\mathrm{pmol} /$ hypothalamus) with a difference in means of $17.6 \mathrm{pmol} / \mathrm{hyp}$ othalamus ( $95 \%$ CI 8.7 to 
26.5). The pituitary oxytocin concentration was not significantly different in the two groups (1902 (84) and 1950 (86) pmol/gland, respectively), the difference in means being -48 pmol/gland (95\% CI -264 to 168). Plasma oxytocin levels were increased $(\mathrm{p}<0.05)$ in hypoxic rats compared with control animals $(6.78$ (1.2) and 3.3 (0.8) pmol/1, respectively) with a difference in the means of $3.48 \mathrm{pmol} / 1$ (95\% CI 0.89 to 6.07 ).

\section{Discussion}

This study is the first to demonstrate that chronic hypoxia stimulates a persistent increase in plasma vasopressin and oxytocin concentrations in conscious rats. There was a progressive increase in plasma vasopressin levels throughout the hypoxic period with peak concentrations occurring after five weeks. The increased hypothalamic hormone concentrations and unchanged pituitary content suggest that prolonged hypoxia stimulates hypothalamic production whilst maintaining a constant enhanced release from the pituitary gland. The mechanism by which hypoxia stimulates hypothalamic hormone production has not been established. Previous studies have demonstrated that intense hypoxia can activate vasopressin-producing magnocellular neurons of the hypothalamic paraventricular nucleus, suggesting a direct effect of hypoxia on the hypothalamus. ${ }^{17}$ Alternatively, hypothalamic hormone production may occur in response to carotid body and aortic arch chemoreceptor and baroreceptor stimulation mediated by changes in gas tension or arterial pressure. ${ }^{18} \mathrm{~A}$ recent study showed that arterial chemoreceptor denervation inhibited the rise in vasopressin in response to acute hypoxia. ${ }^{19}$ In contrast, the increase in vasopressin levels during acute hypoxia has been reported to be independent of blood pressure changes and osmolality. ${ }^{20}$

In this study the increase in hypothalamic hormones occurred in the absence of changes in plasma sodium concentration and osmolality. Vasopressin levels were abnormally high for the measured serum osmolality. At these elevated levels the natriuretic properties of both hormones and the antidiuretic effect of vasopressin would be expected to increase water retention and reduce plasma osmolality. ${ }^{4513}$ This suggests that compensatory mechanisms modulated the actions of these hypothalamic hormones during prolonged hypoxia. A reduction in renal sensitivity to vasopressin and oxytocin during hypoxia would contribute to the raised plasma hormone concentrations as a result of the normal physiological feedback mechanisms. ${ }^{10}$ This hypothesis is supported by the observation that, in hypoxaemic patients with COPD and peripheral oedema, salt and water excretion was reduced following a saline or water challenge and vasopressin levels were inappropriately high compared with the measured serum osmolality, suggesting that renal sensitivity to increased vasopressin secretion was reduced. ${ }^{3}$ However, previous studies have reported that the increased hormone secretion is an ap- propriate homeostatic response to other hypoxia induced physiological changes including reduced renal blood flow, ${ }^{39}$ raised aldosterone levels, ${ }^{411}$ reduced glomerular filtration, ${ }^{10}$ and autonomic dysfunction. ${ }^{312}$

The effect of vasopressin on the renal circulation has not been established but it is recognised that renal blood flow is reduced in oedematous, hypoxaemic patients with COPD. ${ }^{3}$ Vasopressin has potent systemic vasoconstrictor effects, acting via $\mathrm{V}_{1}$ receptors, and may cause coronary artery vasoconstriction and myocardial ischaemia, although this effect is attenuated during hypoxia. ${ }^{21}$ Oxytocin also alters renal haemodynamics and increases the glomerular filtration rate. ${ }^{13}$ The role of these renal effects of vasopressin and oxytocin during the normal physiological response to hypoxia requires further examination. The neurohypophysial hormones may have additional properties that are beneficial during "acclimatisation" to prolonged hypoxia. In particular, vasopressin reverses hypoxic pulmonary vasoconstriction $^{22}$ and improves memory and learning processes that are impaired by hypoxia. ${ }^{23}$ Similarly, oxytocin may act as a pulmonary vasodilator in addition to its natriuretic effects.

This study utilised a rat model to measure hypothalamic hormone changes during prolonged hypoxia in an attempt to reproduce the clinical situation in hypoxaemic COPD. The rat is a standard animal preparation for neurohypophyseal studies ${ }^{1719}$ and has proved to be a reliable model when examining vasopressin release in response to acute hypoxia. ${ }^{6}$ In these experiments rat plasma vasopressin concentrations correlated well with those observed in man under similar conditions. ${ }^{7}$ The increase in PCV during exposure to environmental hypoxia was consistent with the development of severe hypoxaemia and, although the rise in PCV and vasopressin followed a similar time course, the relevance of this is unknown. The value of this model in relation to human disease may be limited by a number of factors. Firstly, a significant proportion of oedematous patients with COPD develop carbon dioxide retention ${ }^{24}$ whereas this rat model is associated with normal or low partial pressures of carbon dioxide. Secondly, rats rarely develop oedema even following prolonged severe hypoxaemia and hypercarbia. Finally, the rats may have failed to drink due to the severity of the hypoxia. The resulting physiological increase in plasma vasopressin concentration due to dehydration would have influenced plasma osmolality and sodium concentrations. ${ }^{48}$ Attempts to measure fluid intake and obtain urinary excretion data to resolve this question failed because of the technical difficulties in measuring these parameters without excessive evaporation due to the high circulating gas volumes in the environmental chambers. To establish the relevance of the results of this study in man will require further investigation, but our data suggest that future human studies should be directed at establishing whether a reduction in renal sensitivity to hypothalamic hormones or altered renal function are 
responsible for the increases in plasma vasopressin and oxytocin levels.

The Special Trustees of St Thomas' Hospital funded the research fellowship of RML and the maintenance costs of the environmental chambers. Dr Yan Zhou kindly helped with the collection of hypothalamic tissue and some of the vasopressin and oxytocin assays.

1 Farber MO, Roberts LR, Weinberger MH, Robertson GL, Fineberg NS, Manfredi F. Abnormalities of sodium and water handling in chronic obstructive lung disease. Arch water handling in chronic obstrut
Intern Med 1982;142:1326-30.

2 MacNee W. Right ventricular function in cor pulmonale. Cardiology 1988;75:30-40.

3 Stewart AG, Waterhouse JC, Billings CG, Baylis PH, Howard P. Hormonal, renal, and autonomic nerve factors involved in the excretion of sodium and water during dynamic salt and water loading in hypoxaemic chronic obstructive pulmonary disease. Thorax 1995;50:838-45.

4 Farber MO, Kiblawa SS, Strawbridge RA, Robertson GL Studies on plasma vasopressin and the renin angiotensin aldosterone system in chronic obstructive lung disease. $\mathcal{F}$ Lab Clin Med 1977;90:373-80.

5 Forsling ML, Ingram DL, Stanier MW. Plasma antidiuretic hormone during hypoxia in anaesthetised pigs. 7 Endocrinol 1980;85:253-9.

6 Jones RM, Larochelle FT Jr, Tenney SM. Role of arginine vasopressin on fluid and electrolyte balance in rats exposed vasopressin on fluid and eltitude. Am 7 Physiol 1981;240:R182-6.

7 Hackett P, Forsling ML, Milledge J, Rennie D. Vasopressin release in man at altitude. Horm Metab Res 1978;10:571-7.

8 Farber MO, Manfredi F. Mechanisms of hyponatremia and edema in chronic obstructive pulmonary disease: clinical significance. Pract Cardiol 1984;10:105-31.

9 Stewart AG, Waterhouse JC, Billing CG, Baylis P, Howard $P$. Effects of angiotensin converting enzyme inhibition on sodium excretion in in converting enzyme inhibition on obstructive pulmonary disease. Thorax 1994;49:995-8.

10 Weekley LB. Angiotensin acts centrally to alter renal sympathetic nerve activity and the intrarenal renin-angiotensin system. Cardiovasc Res 1991;25:353-63.
11 Anderson RJ, Pluss RG, Berns AS, Jackson JT, Arnold PE Schrier, et al. Mechanism of effect of hypoxia on renal water excretion. F Clin Invest 1978;62:769-77.

12 Claybaugh JR, Wade CE, Cucinell SA. Fluid and electrolyte balance and hormonal response to the hypoxic environment. In: Claybaugh JR, Wade CE, eds. Hormonal regulation of fluid and electrolytes. New York: Plenum Publishing, 1989: 187-214

13 Forsling ML, Judah JM, Windle RJ. The effect of vasopressin and oxytocin on glomerular filtration on the conscious rat: contribution to the natriuretic response. $\mathcal{F}$ Endocrino 1994;141:59-67.

14 Forsling ML. Measurement of vasopressin in body fluids. n: Baylis PH, Padfield PL, eds. Posterior pituitary. New York: Markel Dekker, 1985: 161-92.

15 Forsling ML, Peysner K. Pituitary and plasma vasopressin concentrations and fluid balance throughout the oestrous cycle of the rat. $\mathcal{F}$ Endocrinol 1988;117:397-402.

16 Balment RJ, Brimble MJ, Forsling ML, Musabayane CT The influence of neurohypophysial hormones on renal 1986;306:439-49.

17 Kolesnyk IuM, Orestenko IuM, Abramov AV. Interactions of the macrocellular neurosecretory system of the hypothalamus and the endocrine pancreas of rats in adaption to hypoxia. Fiziol $Z h$ 1992;38:30-6.

18 Harris MC. Effects of chemoreceptor and baroreceptor stimulation on the discharge of hypothalamic supraoptic stimulation on the discharge of hypothalamic
neurons in rats. F Endocrinol 1979;82:115-25.

19 Wilson DA, Hanley DF, Feldman MA, Traystman RJ Influence of chemoreceptors on neurohypophysial blood fow during hypoxic hypoxia. Circ Res 1987;61:1194-101.

20 Griffen SC, Raff H. Vasopressin responses to hypoxia in conscious rats: interaction with water restriction. F Endo-

21 Boyle WA, Segel LD. Attenuation of vasopressin-mediated coronary constriction and myocardial depression in the hypoxic heart. Circ Res 1990;66:710-2

22 Jin HK, Chen YF, Yang RH, Mckenna TM, Jackson RM, Oparil S. Vasopressin lowers pulmonary artery pressure in hypoxic rats by releasing atrial naturetic peptide. $A m \mathcal{F}$ Med Sci 1989;298:227-36.

$23 \mathrm{Car} \mathrm{H}$, Borawska M, Wisniewski K. The effect of vasopressi analog: $\left[\mathrm{d}\left(\mathrm{CH}_{2}\right)(1) 5\right.$, Tyr $(\mathrm{Me}) 2$, delta 3Pro7] AVP on learning and memory processes in rats with experimental amnesia. Pol f Pharmacol 1993;45:11-17. 